\title{
The Role of "Citizen Journalist" in the Arab Revolution from the Perspective of the Elites in Arab Media (Syria Model)
}

\author{
AREEJ ALBOSTANGY \\ Universiti Teknologi MARA
}

\begin{abstract}
The Arab Spring has been shaped by successive episodes of the revolutions of freedom, the largest geopolitical movement that has rocked the Arab world since the 1960s. This study aims at determining the role played by the citizen journalist in the Arab spring identify "Syrian revolution". In order to achieve the objective of the study, a questionnaire was designed as the main tool for collecting data. It includes (42) items divided into four variables (credibility, professional, quality and contributions). The sample comprises of 300 individuals' that are selected randomly from all the media elites who work in Jordan. After the distribution of the questionnaire and data collection, the SPSS software was used to answer the study questions through the use of descriptive analysis. The study found that the degree of acceptance of the media elite to the work of citizen journalism ranked first compared to other sources of news, the role provided by the citizen journalist did not rise to the level of the other media, the respondents' estimates of the ability of the "citizen journalism" to fill the vacuum resulting from confusion and official misrepresentation through their technological tools such as the telephone came out clearly against this idea, as there is a significant weakness in the ability of the journalist to apply the standards used in the real media. In light of the results, the study recommends that the findings of the present study show that most of the news and information provided by citizen journalist not credible and not professional.
\end{abstract}

Keyword: Citizen journalism, The Arab Spring, credibility, acceptance, source of news.

\section{INTRODUCTION}

The Arab region has become the subject of controversy; where the situation of Arab spring has created a new media role in promoting freedom and democracy throughout the world, especially the countries of revolutions. This situation allows citizens to find space to spread their views and express their opinions, they refuse to "arbitrarily control their lives. The Syrian Revolution is one of the most prominent events on the Arab and global levels. The Syrian revolution represents one of the greatest humanitarian catastrophes of this age because of the displacement and death of millions of people.

Even though that the Syrian revolution considered the issue of the age, the media coverage of the official channels was weak and difficult, because of the media coverage of the Syrian regime's great reality in the country. In addition to the difficulty of the movement of media personnel inside Syrian territory, because of the multiple killings and kidnappings. Papaioannou and Olivos (2013) pointed out that media coverage of the Syrian revolution was not at the required level, as many things are difficult to access and know the reality because of the inability of the media to collect information and the facts of what is happening within the Syrian territory.

Also, the importance of the need to know what is happening on the Syrian territory, the collection of correct information, and the inability of news channels to do so, appeared the idea of citizen journalism, which includes a citizen to collect information and published in the form of texts or pictures or videos on social networking sites. According to Saifuzzaman 
(2017), several news channels dealt with these people as field correspondents in the Syrian territories, where many interviews were conducted and many videos and articles were published.

Despite all the news and information provided by the journalist to the world at large, whether through social media or news channels, the issue of recognition of the press citizen continues to resonate in the corridors of international organizations as an emergency for the professional journalism world with clear borders. Because This description is not limited to the person who seeks to express himself but extends to include a broad title is "new media professions" such as content users, editors of social networking sites, and photographers working in these networks. Citizen journalism has evolved with citizens turning to alternative media to express themselves freely after some governments, businessmen and traditional media have monopolized Arab countries.

Also, citizen journalism has raised a gap of serious questions, the new style of media about users to producers of informational messages, and achieved the concept of the active public in all its dimensions and moved them from the stage of the active public to the active sender of the media content (Ismael, 2012). Also, the enormous media and technological openness have strengthened the term (citizen journalism), which takes the Internet and social networking sites as an environment. where citizen journalism did not only broadcast the demonstrations and participate in the audio and video programs Such as Skype and IMO, with international news broadcasters but is finally able to provide television reports of various stations such as Al Jazeera and the BBC. Thus playing the role of an experienced journalist at a time when their movements are hazardous due to security prosecution.

This study tries to provide new evidence on the above issues and some understanding about the level of reports in terms of professionalism and objectivity of citizen's journalism, where the argument is that most of the studies in this field did not include the real ability of a journalist citizen to communicate information and news professionally and without bias to any particular party has not been clarified. This thesis addresses the questions over the ability of journalists to access facts and information professionally and professionally, and how that could impact world opinion.

Modern means of communication have enabled individuals to write and produce media content even if they are not professional journalists and are published on the World Wide Web and even broadcast on television, radio and news agencies, the widespread use of modern communication tools and technologies in large segments of the society and their ease of use by individuals have led to the creation of materials and information by citizens, which have often competed and match the contents of traditional media, has emerged many new spaces and technologies that allow the possibility of dissemination and broadcast these contents without any censorship or pressure, such as (YouTube) (Seth et al., 2009).

The electronic media imposed a new media reality by all standards, where it moved the news from television programs and press to wider and larger areas, which enhanced the availability of news through penetration of all spatial, temporal barriers and endless diversity of news and information. Therefore, the Internet through social networks has dominated the media (Wall \& el Zahed, 2014). 


\section{a. Research Background}

\section{LITERATURE REVIEW}

Nowadays, one of the most international issues in the world is Arab revolutions, this issue has interested many researchers around the world particularly the news and information about this issue, whether from its reliability or sources, which varied especially with the existence of social networks. Therefore, a large number of studies have done on this topic. However, this issue still needs more study to describe the role and extent which are allowed by these sources to provide accurate and diverse information.

The Arab region has become the subject of controversy; whether by politicians or researchers, it has become the most controversial in their transformations, particularly after so-called (Arab Spring). On the other hand, the development of social media make it became a very powerful media force among young people in particular, and these sites have the opportunity to turn each participant from a reader to a source for the production of media material and consumption at the same time (Yaseen, 2012).

Depend on what has been discussed above; the situation of Arab spring has created a new media role in promoting freedom and democracy throughout the world, especially the countries of revolutions. This situation allows citizens to find space to spread their views and express their opinions, they refuse to "arbitrarily control their lives." Citizen journalism has evolved with citizens turning to alternative media to express themselves freely after some governments, businessmen and traditional media have monopolized Arab countries.

Since the beginning of the Arab revolutions in 2010, most Arab and international news channels have used the citizens of these countries as journalists to cover the hot events in their countries. In Syria, for example, the organization of "citizen journalism" has developed significantly throughout the Syrian revolution; citizen journalism in Syria was divide into two groups: internal and external media team (Ismael, 2012).

Also, if the recent Arab revolutions were born through electronic social networking sites, the media coverage of these revolutions turned the standards of the Arab media after the invasion of "citizen journalism", which abolished all attempts to suppress and blackout media. Thus, citizens have become a major source of information, and the citizen's press has become a reliable basis for most of the events of the revolutions (Ismael, 2012).

Where the restrictions imposed on the old media prompted citizens in the Arab world to search for new channels of communication and flee to the virtual world. The Arab Spring confirms the use of protest movements for social media to invite protest and pretend to be in the real world.

In summary, the present study is an effort to evaluate and examine the role of "Citizen Journalist" in the Arab revolution. This study motivated by several factors including the lack of empirical reviews about this issue especially about the Syrian revolution, and the need to more understanding about the role of "Citizen Journalist" in the Arabs revolution to make the findings more reliable and meaningful.

\section{b. Research Questions}

The study seeking to answer the following questions:

$\mathrm{RQ}$ 1. What is the extent of accept of the media elite to the work of the citizen journalist?

RQ 2. What is the role of "Citizen Journalist" in the Arab Revolution?

RQ 3. What is the ability of "Citizens Journalist" to fill the vacuum created by the official obfuscation and misinformation through their technological tools like a phone? 


\section{c. Significance of the Study}

The news has the most significant in influencing an individual's behaviour towards other people. Since this study is to determine the role of "Citizen Journalist" in the Arab revolution from the perspective of the elites in Arab media, the significance of the study carries out a new angle and perspective. Simultaneously, lack of studies has been found on the Citizen Journalist in Syria, in comparison to the large number the studies on the Citizen Journalist in the World. Thus, the findings of this study are beneficial to both sides of the Arab world and global. The findings with empirical data are useful to the policymakers, the government in terms of preparing media policy and establishing media channels for providing real knowledge.

In this regard, identifying the Citizen Journalist role will enhance a better understanding and strengthen the real perception of the citizen's ability to deal professionally and professionally with the news and information. Moreover, some of the news and information circulated about the Syrian revolution and the reality of what is happening on the Syrian territory is not real and fake, so it is necessary to ascertain the source of the news and the accuracy of its presentation to the citizen, considering that such news affects the ability of citizens to know the reality of what is going on, thus influencing their attitudes and behaviours. This study contributes to providing more understanding about the role of the citizen Journalist in Syria and increasing the knowledge of researchers in the field of Citizen Journalist, media, broadcasting, and social network.

In short, by identifying the role of the citizen Journalist in Syria the Arabs and world will be more understanding in the type of news that provides by citizen Journalist whether in terms of credibility, health or impartiality of one party on the other. This study also hopes to encourage the role of news channels in providing real news and information about the situation in Syria.

Also, it highlights the importance of this study by addressing the issue of the Syrian revolution and the many conversations and news that have been circulated about what is happening on the ground, but the fact and credibility of what is transferred from the news is unknown, as there are many inaccuracies about what is transferred from news, therefore this study is important to clarify these inaccuracies and to ascertain the credibility of what is transferred from the news.

\section{d. Citizen Journalist and Syrian Revolution}

With the beginning of the Syrian revolution in March 2011, the regime has been tightening the media in Syria to the point of preventing any unofficial media coverage or under official supervision of the events to isolate what is happening in Syria from the world and the ability to control internally and externally. The Syrian media itself was created again by the people who turned into journalists, and then to journalist's citizens, especially with the availability of social media, which became available to all, can no longer System or any other party Innovation media platforms within the traditional media (Mahmood et al., 2014).

Since the Syrian crisis, hundreds of thousands of political activists have been kidnapped and dozens of young people have been killed by sniper fire or under torture, while their weapons were mobile lenses that monitored scenes of daily killing, shelling, destruction and displacement. Those who succeeded in documenting the image from the ground of the event and transferred the voice of Syria to various regions of the world, and they are the ambassadors of truth, under the name of a new job; citizen journalist (Saifuzzaman, 2017). 
With the revolutionary Syrian revolutionary movement, the need for media activity to convey the suffering of peaceful demonstrators has increased with full media control of the Syrian regime and its repressive apparatuses, which practised various kinds of "media blackout" and "disinformation", intending to deny any peaceful movement against the regime (Ismael, 2012). Because the need is the mother of invention, it was necessary to find the "parallel" or "alternative" media against the authority media, so emerged the phenomenon of "media activist" or "citizen journalist" that was able to deliver the voice of peaceful demonstrators to the outside world. Despite the weakness of professionalism and experience, citizen journalist has also been very successful in attracting supporters for oppressed people who want their freedom through the Syrian revolution (Murad, 2012).

Citizen journalism was the first form of free Syrian modern journalism, built on courage and the desire to say the truth above all to say: The Arab Spring revolutions born from the womb of social networking sites. Media coverage of these revolutions turned the standards of the Arab media after the invasion of "citizen journalism" in the voice and image, striking out all attempts at repression and opacity adopted by the regimes of these peoples (Hanan, 2015).

The security situation imposed by the Arab regimes, whose countries have witnessed conflicts and the harsh response to all the media that tried to transfer events, whether by closing the offices of the channels and newspapers or by arresting correspondents and journalists, that has been pushed many to be citizen journalists, not waiting for editor's orders or instructions for a particular event, but conveying what is happening around them as it is. The protracted circumstances of the conflict have led to the development of the need for professional journalism, which is no longer merely a state of affairs (Wall \& el Zahed, 2014).

The Syrian government expelled many foreign journalists, making verification of the violence almost impossible. In order to overcome this blackout, the demonstrators resorted to their cell phones to demonstrate their demonstrations and accompanying repression and then spread those films on the Internet using proxy programs to not arrest them (Hanan, 2015).

Journalists in Syria were not seen as observers, as Assad's media machine portrayed the uprising as a foreign conspiracy carried out by terrorists and declared that anyone who criticized the regime was a terrorist and deserved death. Meanwhile, as events in Syria escalated, a group of journalists began to break the media monopoly of information and set up a group on the Facebook website called "Syrian Liberation" to publish reliable and accurate news about what was going on the earth (Wall \& el Zahed, 2014).

Social media played an important role in the Arab Spring revolutions, especially in Tunisia and Egypt. In 2011, during the coinciding of the Arab spring revolutions, Mrs Fidaa Al Sayed established a Facebook page on behalf of the Syrian Revolution Network, which attracted more than 383,000 fans in a few days. The page has published reports and news related to the uprising and has provided general guidelines as well as organizing protests (Hanan, 2015).

The citizen's journalism contributed to igniting the events of the Arab Spring revolutions and sought to ensure their continuity, and attention about it, while providing constant news and media coverage, and to mobilize the masses to participate in the making of those events. Also, the citizen's journalism through blogs and social networking sites, especially Facebook, has exceeded the social framework for which it was founded, to become an effective media and political player in the Arab world (Mahmood et al., 2014). 


\section{METHODOLOGY}

This research avoids using a survey approach to collect information from the elites in Arab media. According to Popper (1959) the questionnaire considered as a suitable instrument for this study, because it is the best way to get new information and facts not provided by other sources, it is characterized by the ease and speed of distribution by mail on a wide geographical area, save time and costs, and it gives the respondent the freedom to make any information he wants.

This study used a questionnaire, based on the Likert scales, consisting of five choices ranging from strongly agree and strongly disagree to a relative weight (1-5). The questionnaire divided into two main sections, the first concerned with the personal data of the respondents, while the second about the subject of the study and includes a set of paragraphs that relate to four aspects (credibility, professional, quality, and contributions).

The target population of this study is elites in Arab media who work in Jordan, totalled about (1500) individuals. According to Cavana et al. (2001), the required sample size for this study will be about (306) founded on the rules provided by Krejcie and Morgan (1970) for sample size decisions, and according to Fox et al. (2009) with $95 \%$ assurance level and $+/-5 \%$ margin of error, (321) sets of the questionnaire are going to be distributed to the respondents in case of the occurrence of unused data. This present study adopts two theories which could illustrate the role and the influence of citizen journalism in Arabic revaluation. They are described in the following sub-sections:

\section{A. Media Dependency Theory}

Undoubtedly, as societies grow more complex and technology improves, the expansion of audience needs that media fill is extended. Then the assumption could be that the bigger the amount and centrality of the particular information given by a certain media's medium, the greater the people's reliance on it. Essentially, the dependency on media also increases with the increase in changes and conflicts in societies. Moreover, the theory of media dependency concludes that "the potential for mass media messages to achieve a broad range of cognitive, affective and behavioural effects will be increased when media systems serve many unique and central information delivery functions. That potential will be further increased when there is a high degree of structural instability in society due to conflict and change." Furthermore, it is important to take account of the fact that "altering audience cognitive, affective and behavioural conditions can feedback in turn to alter both society and the media" (DeFleur \& Ball-Rokeach, 1989, p.263).

Based on the models, dependency theory predicts that an individual depends on the information of media to obtain particular needs and reach particular goals however he does note equally rely or depend on every medium. In this relation, there are such factors that could influence an individual towards media dependency. Firstly, the individual will get to be more reliant on media that addresses his various issues compared to one that just addresses his or her needs. Secondly, social stability is the dependency source. At the point when social change and clash are high, an individual's beliefs, and practices challenge established institutions and they force the individual to be more dependent on the media to make a new choice. Hence, the needs of the people are not personal because they may be shaped by various social conditions and culture. In relation to the news sources that audiences depended on to watch news of Arab Spring, a study by Sofi and Burihi (2014) determined the most important news source being used by the elite of the Arab Academicians in Yemen. In their study, the findings showed that the satellite news channels were the first and the 
preferred channels for them, and they were Aljazeera Arabic news then Arabic, then the "BBC", then Al-Hura channel. The Yemeni private channels came as second options and the social media as the third option of sources for them.

As this present study determines the role of citizen journalism in the Arab Spring (Syrian revolution news), therefore, this theory is related to this present study, where the dependency theory composed many assertions, including "in our modern industrial society we are increasingly dependent on media to understand the social world, to act meaningfully and effectively in society and to find fantasy and escape or diversion. Second, the basis of the media's influence resides in the relationship between the larger social system, the media's role in that system and audience relationship to the media. Third, the degree of our dependence on media and their content is the key variable in understanding, where the media message can change the beliefs, feelings, and behaviour of audience" (Ball-Rokeach \& Defleur, 1976).

\section{B. Theory of Technological Determinism}

This study is based on the theory of technological determinism, which is known as the technological theory of the media, which is one of the modern theories that have emerged to show the role of the media and the nature of its influence on different societies and the creator of this theory (Marshall McLuhan). Technological determinism is a theory which assumes that changes in technology are the primary source for changes in society. A society's technology determines the development of its social structure and cultural values. Technological determinism tries to understand how technology has had an impact on human action and thought (McLuhan \& Lapham, 2012).

Marshall McLuhan says that the "content" of the media cannot be seen independent of the media technology itself. How the media organizations present the issues, and the public to whom it addressed its mission, affect what these means say, but the nature of the media that relate to the human form communities more than the content of the communication, that is why McLuhan calls his technological theory determinism. While Karl Marx believed in economic determinism and that the economic organization of society was an essential aspect of his life. While Freud believed that sex played an essential role in the life of the individual and society, McLuhan believed that important technological inventions had a fundamental impact on societies (McLuhan \& Lapham, 2012).

Media determinism is a form of technological determinism, a philosophical and sociological position which posits the power of the media to impact society (Williams, 1974). Two foundational media determinists are the Canadian scholars Harold Innis and Marshall McLuhan. One of the best examples of technological determinism in media theory is Marshall McLuhan's theory "the medium is the message" and the ideas of his mentor Harold Adams Innis. Both these Canadian theorists saw media as the essence of civilization. The association of different media with particular mental consequences by McLuhan and others can be seen as related to technological determinism. It is this variety of determinism that is referred to as media determinism. According to McLuhan, there is an association between communications media/technology and language; similarly, Benjamin Lee Whorf argues that language shapes our perception of thinking (linguistic determinism). For McLuhan, media is a more powerful and explicit determinant that is the more general concept of language. McLuhan was not necessarily a hard determinist. As a more moderate version of media determinism, he 
proposed that our use of particular media may have subtle influences on us, but more importantly, it is the social context of use that is crucial (McLuhan \& Lapham, 2012).

\section{RESULTS AND DISCUSSION}

\section{A. The Acceptability of the Media Elite to the Work of the Citizen Journalist}

The study results indicated that the degree of acceptance of the media elite to the work of citizen journalism ranked first compared to other sources of news (such as television and newspapers), where the percentage of follow-up media elite of the events of the Syrian revolution through the work of the citizen journalist amounted to $(52.3 \%)$, which is greater than the percentage of the media elite following the events of the Syrian revolution through television $(39.0 \%)$ or newspapers (8.7\%).

The researcher due this result to the media blackout that the Syrian regime exercised over the reality of the events taking place during the Syrian revolution, in addition to preventing the Syrian regime from entering the country and covering the marches and protests from the beginning of the Syrian events. These reasons led many media elites to follow up on the news that the (citizen journalist) is conveying, considering that it is the only source available for the transfer of events taking place on Syrian territory.

In addition, the widespread of the Internet and technology tools has increased the volume of people's follow-up to the news that is transmitted by the citizen. As the availability of free websites, such as social networking sites and blogs contributed significantly to the tendency of many individuals to abandon the traditional media and follow up what the journalist publishes the citizen news and articles.

Also, the social media played a major role in igniting and sustaining all the revolutions of the Arab Spring, including the Syrian Revolution, and contributed to the formation of an alternative media in light of the strong media monopoly of the ruling regimes, especially in the early years of the revolutions, which extend from the end of 2010 and 2011-2012. In 2012, more than five million Syrians were using the Internet, and the percentage of using Facebook reached $(17.4 \%)$, where Facebook is one of the most popular social media, followed by YouTube and Twitter, and uses the means of communication by youth groups in particular, who received Education between secondary school and postgraduate studies (Hanan, 2015).

The use of social media is widely used by all members of the society (both inside and outside Syria) to know and follow the news, because of its easy use, speed of transmission of news and pictures, and video clips of their own and their spread, with the possibility of expressing various views and comments freely without restrictions. All these reasons provided an environment conducive to the spread of the phenomenon of citizen journalism at the global level.

Alaoneh (2017) pointed that the media elite in particular and all segments of society in general, follow the news and information conveyed by the journalist citizen, due to the inability of satellite channels and other media to cover the events of the Syrian revolution, because of the prevention of journalists from entering Syria and the difficulty of transferring events through the traditional media, except for the official media of the Syrian regime. This has greatly affected the percentage of follow-up and acceptance of the work of the journalist citizen, as well as by the media elite or the rest of the society.

\section{B. $\quad$ The Role of "Citizen Journalist" in the Arab Revolution}

The study results showed that the role of citizen journalist in the Syrian revolution, where the arithmetic mean was (2.89), and standard deviation (.557), this indicates that the role 
provided by the citizen journalist did not rise to the level of the other media.

The researcher due this result to the phenomenon of the citizen journalist was linked to the peaceful popular movement at the beginning, but with the complexity of the conflict and its development into armed action, the "alternative media" lost some credibility and fell in some problems and shortcomings despite its relative superiority within the possibilities available to it.

C. The Ability of "Citizens Journalist" To Fill the Vacuum Created by the Official Obfuscation and Misinformation Through Their Technological Tools Like a Phone

The study result showed that, the respondents' estimates of the ability of the "citizen journalism" to fill the vacuum resulting from confusion and official misrepresentation through their technological tools such as the telephone came out clearly against this idea, where the answer (No) ranked first and by the percentage (74.7\%), the answer (sometimes) came at the second rank and by the percentage (16\%), and in the last rank came the answer (Yes) and by the percentage (9.3\%).

The researcher due this result to that the media work needs more than just a mobile phone and the Internet, as it requires skills and high capabilities cannot be anyone without receiving the appropriate training, which helps him to perform his work better. In addition, the work of the media requires the availability of a variety of modern tools and sophisticated, as the adoption of citizen journalist on the phone alone is not enough, considering that the camera phone cannot shoot with high accuracy.

The mere possession of Mobile's press citizen does not enable him to keep up with the official media, which has various satellite channels and satellites capable of delivering its message to all parts of the world, where the citizen journalist has only the mobile and the Internet in order to transfer events in the Syrian territory, which means that the interruption of the Internet leads to the inability of the journalist citizen to transmit the news.

\section{CONCLUSION}

The results indicated that the majority of the respondents use the internet to follow the citizen journalist to obtain news and get information about the Syrian revolution. Based on the models, dependency theory predicts that to gain certain needs and achieve certain goals, an individual depends on media information, but an individual's dependency on all media is not equal. It is important to point out that two factors influence individual dependence on media. Firstly, an individual's media dependency will be more if certain media meets a number of his needs compared to others. Secondly, social stability is also a source of media dependency. When social change and conflict are high, an individual's beliefs, practices, established institutions are challenged and they force the individual to be more dependent on the media to make a new choice. Hence, the needs of people are not personal because it may be shaped by various social conditions and culture. Therefore, in this regard, the media elite depend more on the internet, blogs and social networks sites, since the Arab Spring uprising was started.

\section{BIODATA}

Areej Albostangy is a PhD student at Mass Communication and Media Studies, Universiti Teknologi Mara. Email: areej.albustanji@yahoo.com 


\section{REFERENCES}

Alaoneh, H. (2017). Citizen journalism as a source of information from the perspective of Jordanian journalists, survey study. Jordanian Journal of Social Sciences, 10(2).

Ball-Rokeach, S. J., \& Defleur, M. L. (1976). A dependency model of mass-media effects. Communication Research, 3, 3-21.

Cavana, R., Delahaye, B., \& Sekeran, U. (2001). Applied business research: Qualitative and quantitative methods. OAl, Research gate.

DeFleur, M. L. \& Ball-Rokeach, S. (1989). Theories of mass communication (5th ed). White Plains, NY: Longman.

Fox, N., Hunn, A., \& Mathers, N. (2009). Sampling and sample size calculation. This Resource Pack is one of a series produced by The NIHR RDS for the East Midlands / The NIHR RDS for Yorkshire and the Humber. This series has been funded by The NIHR RDS EM / YH.

Hanan, B. (2015). The role of social networking sites in activating the citizen's journalism, a field study for a sample at Umm al-Boaqi University, Facebook as a model (Master Thesis, University of Arabi Ben Mehdi, Algeria).

Ismael, H. (2012). The role of citizen journalist movement in the Syrian point of view of the opinion leaders of the Arab media (Jordan, Kuwait, Egypt model) [Master Thesis, MEU, Jordan].

Mahmood, Q., Firdaus, A., \& Adnan, H. (2014). Social Media and arab revolts: An appraisal. Jurnal PengaJian Media Malaysia, 16(2), 1-15.

McLuhan, M., \& Lapham, L. H. (2012). Understanding media: The extensions of man. US: MIT Press. Retrieved on March 24, 2012.

Murad, A. (2012). Journalist citizen in the official media directory. Al Bayan (Lebanese newspaper).

Papaioannou, T., \& Olivos, H. E. (2013). Cultural identity and social media in the Arab Spring: collective goals in the use of Facebook in the Libyan context. Journal of Arab \& Muslim Media Research, 6(2).

Popper, K. R. (1959). The logic of scientific discovery. New York: Basic Books.

Saifuzzaman, A. (2017). Impact of social media in Arab spring: Special emphasis on Tunisia's uprising. International Journal of Development Research, 7(8).

Seth, C., Lewis, K., \& Dominic, L. (2009). Thinking about citizen journalism: Perspectives on participatory news production at community newspaper. Journalism Practice, 4(2). https://doi.org/10.1080/14616700903156919

Sofi, K., \& AL-Buraihi, A. (2014). The role of media in formatting the attitude of elites of Arab academicians in Yemen towards the "Arab Spring»: Strategic visions. The Emirates Centre for Strategic Studies and Research, 2(5), 31-74.

Wall, M., \& el Zahed, S. (2014). Syrian citizen journalism, a pop-up news ecology in an authoritarian space. Digital Journalism, 3(5).

Williams, R. (1974). Television: Technology and cultural form (p. 133). London: Routledge. Retrieved on 28 May 2019.

Yaseen, S. (2012). Revolution and democratic transition in the Arab world towards a road map. Beirut: Center for Arab Unity Studies. 